\title{
Qual o Planejamento Regional na Sociedade de Risco? \\ Reflexões para uma Renovação da Agenda de Pesquisa no Rio Grande do Sul
}

http://dx.doi.org/10.21527/2237-6453.2019.47.238-247

Recebido em: 22/5/2017

Aceito em: $17 / 12 / 2018$

\section{Markus Erwin Brose ${ }^{1}$}

\begin{abstract}
RESUMO
A percepção de riscos pela mudança do clima fomenta a rediscussão das prioridades da pesquisa sobre o planejamento regional. Mudança climática não se resume a um "tema ambiental", altera relações de poder nos mercados, mediante alteração de preços, e na política, por meio de novos custos. Este artigo tem como objetivo uma reflexão em base empírica, contribuindo para integrar a resiliência como dimensão transversal no planejamento regional. Utiliza aspectos da teoria da Sociedade de Risco, proposta pelo sociólogo Ulrich Beck, discutindo conexões com a obra de Anthony Giddens, em especial sua proposta do New Green Deal. Argumentamos que, contrariando o otimismo de Giddens quanto à capacidade do Estado, é possível reconhecer no Rio Grande do Sul evidências do esgotamento dos clássicos conflitos redistributivos do capitalismo e que incertezas crescentes estimulam a renovação nas prioridades da pesquisa em planejamento regional.
\end{abstract}

Palavras-chave: Riscos. Modernidade reflexiva. Planejamento regional. Rio Grande do Sul.

WHAT KIND OF PLANNING IN A RISK SOCIETY? REFLECTIONS FOR A RENEWAL OF THE RESEARCH AGENDA IN RIO GRANDE DO SUL

\begin{abstract}
The perception of risks due to climate change encourages a re-discussion of research priorities on regional planning. Climate change is not just an 'environmental issue', it alters power relations in markets, by changing prices, and in politics, through new costs. This article aims at an empirical reflection, contributing to integrate resilience as a transversal dimension in regional planning. He uses aspects of the Society of Risk theory, proposed by sociologist Ulrich Beck, discussing connections with the work of Anthony Giddens, especially his proposal of the New Green Deal. We argue that, contrary to Giddens' optimism as to the capacity of the state, it is possible to recognize in Rio Grande do Sul evidence of the exhaustion of the classic redistributive conflicts of capitalism, and that increasing uncertainties stimulate the renewal of research priorities in regional planning.
\end{abstract}

Keywords: Risk. Reflexive modernization. Regional planning. Rio Grande do Sul.

\footnotetext{
${ }^{1}$ Doutor em Sociologia pela Universidade de Osnabrück/Alemanha. Professor do Programa de Pós-Graduação em Desenvolvimento Regional da Universidade de Santa Cruz do Sul (Unisc).markus@unisc.br
} 
A cultura política gaúcha é marcada pela concepção do Desenvolvimentismo. Em síntese, uma perspectiva otimista, tributária da Teoria da Modernização, de que o Estado é capaz de identificar problemas do território, mantém capacidade técnica para selecionar as melhores soluções para superação dos gargalos do desenvolvimento e dispõe dos recursos financeiros necessários para intervir na economia de forma sustentada, oferecendo, em longo prazo, subsídios e estímulos que redirecionam o comportamento das famílias e das empresas.

O paradigma do Desenvolvimentismo consolidou-se ao longo de um século no Rio Grande do Sul (RS), desde 1883, mediante experiência singular de quatro décadas de governos de orientação positivista, experiência cujas linhas mestras foram levadas à esfera nacional pelo governo Vargas. Originado em formato de regime autoritário, o paradigma foi renovado em período democrático pela administração Brizola, nos anos 60, e novamente na redemocratização, desde 1985 , por meio da criação de Conselhos Regionais de Desenvolvimento, Consulta Popular e Orçamentos Participativos, inovações gaúchas para acesso e controle do orçamento público.

Desde os anos 2010 observa-se o fim dos titânicos embates ideológicos que marcaram a redemocratização gaúcha, substituídos pelo debate sobre o déficit fiscal. 0 crescente esvaziamento dos Conselhos Regionais de Desenvolvimento é identificado pela redução do número de participantes, baixos índices de renovação dos delegados, acúmulo de demandas não contempladas pelo orçamento estadual ou a substituição de projetos estratégicos por demandas ordinárias, como ambulâncias para hospitais ou coletes para policiais. E também pela extinção do simbólico Orçamento Participativo em Porto Alegre, de fato, pelo fim do superávit orçamentário, de direito, transformado de um espaço de deliberação em mais um fórum de consulta. Nos demais municípios do Estado que adotaram o Orçamento Participativo, ele entrou para a história.

Esse contexto apresenta similaridades ao diagnóstico apresentado pelo sociólogo Ulrich Beck que, em meados dos anos 80, argumentou que as sociedades europeias estavam em transição para uma nova modernidade (BECK, 2010b). Propôs substituir o conceito de pós-modernidade pela ideia de segunda modernidade, na medida em que as categorias dos conflitos redistributivos do capitalismo industrial clássico, como a luta de classes, estariam se esgotando em sua capacidade de interpretação da sociedade. Beck argumenta que as sociedades estariam em transição para novos problemas e novos desafios, o que denominou como transição para a Sociedade de Risco, que demandaria novas formas de participação e de planejamento.

Tese central do conceito de Sociedade de Risco sustenta que a produção do capitalismo industrial vem acompanhada, em escala crescente e em ritmo exponencial, da fabricação e distribuição de riscos (genéticos, nucleares, químicos). Desde os anos 70/80, uma característica determinante das sociedades europeias residiria nos impactos negativos da produção de bens de consumo em massa que não afetam mais apenas as classes vulneráveis, como no caso de operários vivendo na vizinhança de fábricas poluidoras, mas que afetam potencialmente a todos, criando novas desigualdades.

Segundo Beck, na segunda modernidade o impacto da contaminação do ar, da água e dos alimentos pode ser maior nas classes vulneráveis, porém o risco foi democratizado. E os clássicos mecanismos de proteção pelo Estado, como políticas públicas de saúde ou de controle ambiental, não seriam mais suficientes para garantir segurança 
ao cidadão. Nesse contexto, o sociólogo Anthony Giddens (2008) propôs a renovação do pacto social nos países europeus, por meio de um New Green Deal. O novo pacto teria como prioridades tanto a redução das emissões dos gases de efeito estufa como a adaptação aos impactos da mudança do clima.

O RS figura entre os maiores emissores de gases de efeito estufa do país, dada a extensão da pecuária de corte e as lavouras de arroz irrigado. O enfraquecimento da capacidade do Estado, identificável pelo déficit fiscal, o endividamento insustentável ou a minimização do investimento em infraestrutura, ocorre concomitante à expansão em número e em intensidade de desastres naturais. Secas, alagamentos e deslizamentos são mais frequentes e causam maiores prejuízos. Desde 2012 o governo estadual qualificou o sistema de defesa civil, aumentou a capacidade de resposta nos municípios e criou uma sala de situação, o que amplia o compromisso do orçamento estadual, sem que essa inovadora política pública de resiliência, fomentada pelo Banco Mundial, tenha passado por uma das tradicionais instâncias participativas, como consulta pública, conselhos regionais ou orçamentos participativos.

Propomos a hipótese de que o RS apresenta indicadores objetivamente verificáveis de que está experimentando os impactos da mudança climática (GIMÉNEZ, 2006; FOCHEZATTO; GRANDO, 2011; SCOTTÁ, 2013), visível por ressacas mais fortes, que destruíram moradias na praia de Hermenegildo, em outubro de 2016; sensível para plantas e animais, pelo aumento da temperatura média no Pampa; ou ainda, a histórica enchente do Guaíba, em outubro de 2015, que ameaçou patrimônio público e privado. Isso torna plausível o argumento de que a sociedade gaúcha se encontra em transição para uma segunda modernidade.

Este artigo discute essas questões, passando pelas dificuldades impostas pela retração do Estado do Rio Grande do Sul às tradicionais ferramentas de planejamento regional. A partir da contextualização pelos aportes teóricos de Beck e Giddens, revisa (ainda) escassas experiências de gestão territorial em novas bases, priorizando o planejamento por bacias hidrográficas. Por fim, discute os possíveis avanços nas políticas públicas, considerando, por um lado, as dificuldades colocadas pelas restrições do orçamento estadual e, por outro, pelos avanços e inovações oriundos de atores locais.

\section{APORTE TEÓRICO: \\ A Transição para a Sociedade de Risco}

Em essência, Ulrich Beck argumenta que a ciência, a tecnologia e o Estado não são mais competentes o suficiente para mitigar riscos nas sociedades europeias. Ao contrário, estariam ampliando os riscos no capitalismo pós-industrial. A publicação de seu primeiro livro discutindo essa hipótese (BECK, 2010b) coincidiu com a expansão da nuvem radioativa de Chernobyl, e três anos depois, com a queda do Muro de Berlim, ambos os eventos realçando a ausência de fronteiras espaciais ou temporais para a disseminação de riscos. O autor exortou a ciência, em especial a Sociologia, a renovar-se, pois corria o risco de se tornar uma "loja de antiguidades".

Segundo Beck, na tentativa de prevenir, ou ao menos remediar, os riscos e prejuízos produzidos em escala industrial pela modernização do capitalismo, a sociedade passa a lidar com impactos não previstos, o que denominou, inicialmente, de segunda modernidade. Em diálogo com os trabalhos de Anthony Giddens, ambos os autores 
passaram a se referir à modernidade reflexiva. Reflexiva, pois a própria modernização torna-se objeto de escrutínio contínuo, passa a representar um problema na opinião pública e na pesquisa acadêmica. Não há mais a segurança implícita na ideia popular de que o avanço da ciência, mais cedo ou mais tarde, irá solucionar problemas cada vez mais graves, como mobilidade urbana, poluição dos recursos naturais ou depauperação dos estoques de pesca.

Diante da sensação de insegurança, reforçada por fatores decorrentes da modernização global, como desemprego e crises recorrentes, o cidadão tende a se tornar consciente das contradições e limitações da sociedade industrial, passando a questionar, ou mesmo a duvidar das instituições, incluindo a dúvida quanto à relevância do conhecimento científico. A modernização volta-se contra si mesma e Beck argumenta que na modernidade reflexiva a opinião pública passa a revisar e alterar continuamente as práticas sociais. Há minimização do papel da tradição, a vida não mais é vivida apenas como destino.

A modernidade pós-industrial caracteriza-se por riscos invisíveis, de difícil mensuração, que, quando se acumulam em desastres, causam prejuízos praticamente incalculáveis. Pelo crescente isolamento e individualismo do cidadão, este passa a duvidar da segurança dos alimentos, da água, da veracidade do noticiário e das informações científicas. Torna-se mais fácil a disseminação de boatos, o surgimento de profetas das pseudociências e dos políticos com plataformas carismáticas, ou apocalípticas, que colocam em risco conquistas da democracia. Beck (1999) alertou que a crescente adesão a ideias neoliberais ampliaria o risco de "brasilianização" nos países centrais, ou seja, a difusão do "jeito", a erosão do Estado de Direito, a precarização do mercado de trabaIho. Cunhou a expressão "irresponsabilidade organizada" (BECK, 1988) para caracterizar o número de riscos, sem que seja possível ao indivíduo atribuir culpa direta a um causador único (AVZARADEL, 2012).

Risco e reflexividade constituem os elementos centrais da etapa atual das sociedades europeias, que configuram uma Sociedade de Risco. Beck (2010a) ampliou o debate, incorporando às suas reflexões a mudança climática, ressaltando que esta deixa de ser um tema ambiental para tornar-se um risco econômico às potencialidades do desenvolvimento. Além disso, conclamou a ação decidida para adaptação e mitigação à mudança do clima, o que inclui a convivência em uma cultura de incertezas, dependendo de maior capacidade para planejar para maior resiliência e menor grau de previsibilidade.

Para Giddens, a característica central da conceituação de riscos manufaturados, produzidos pelo sistema, como proposta por Beck, é a de que a sociedade vive além dos limites da tecnologia, numa fronteira ampliada na qual não é mais possível compreender ou ter domínio completo das consequências, mas que carrega uma dimensão positiva, de novas possibilidades de mobilização social, engajamento e participação. Diante das ameaças e incertezas impostas pela mudança climática, Giddens propõe um novo pacto social, que denomina de New Green Deal, como referência ao sucesso do New Deal, as políticas keynesianas adotadas para a reconstrução da economia dos EUA após a recessão desencadeada pela quebra da Bolsa de Valores de Nova York, em 1929. 
A proposta de um novo pacto social, liderado por um Estado forte, com elevada capacidade de planejamento e alocação de recursos, encontra ressonância em países centrais. Como o Reino Unido, que se tornou liderança continental nas ações de mitigação e adaptação em mudança climática, ou a Alemanha, que assumiu o compromisso de eliminar a energia nuclear a partir de 2022 e está descentralizando a geração de energia para fontes renováveis.

Contrariando o otimismo de Giddens quanto aos países centrais, argumentamos que, no RS, uma região marcada pelo déficit fiscal, pela descontinuidade das políticas públicas e a fragmentação da capacidade de planejamento em longo prazo, evidenciada, por exemplo, pelo insucesso do Polo Naval de Rio Grande, a sociedade não deve esperar do Executivo a liderança na mitigação e adaptação aos riscos da mudança do clima. Isso reforça a pergunta provocativa proposta por Beck:

Sem uma maioria composta por grupos sociais muito diversos, que não apenas falem sobre, mas, que atuem e votem a favor de políticas públicas relacionas ao clima [...] a ação pública não terá futuro. Apenas se encontrarmos resposta à questão urgente e pouco debatida: de onde virá o apoio cotidiano da população, o suporte pelas mais diversas classes, diferentes nações e ideologias, que são afetadas de forma diversa pela mudança climática? Somente então as políticas de mudança climática perderão seu status elitista (BECK, 2010b, p. 255). ${ }^{2}$

Beck enfatiza, assim, a necessidade de maior informação e engajamento no debate público sobre a mudança climática para além da ação regulatória do Estado. Esse argumento vem de encontro aos resultados de pesquisa de opinião encomendada, apenas quatro anos mais tarde, pelo Ministério da Ciência e Tecnologia quanto ao interesse da população brasileira em divulgação científica. No quesito "Percepções de risco e questões socioambientais no Brasil", o maior grau de preocupação dos entrevistados foi com o "desmatamento na Amazônia", e em segundo lugar, com os "efeitos da mudança climática". Os autores do relatório sugerem que as respostas não estão associadas ao medo pela população, mas, "a uma preocupação que alimenta um comprometimento e um interesse por uma maior apropriação e participação nessas temáticas e discussões" (CENTRO..., 2017, p. 85).

Argumentamos, parafraseando Beck: De onde surgem inovações na adaptação à mudança climática que possam enriquecer o debate público e renovar a pesquisa?

\section{Qual o Planejamento para as Incertezas?}

O desafio para o planejamento territorial com ambiguidades não é novo. As primeiras ideias sobre o planejamento com incertezas, propostas pelo professor Horst Rittel em debates na Universidade da Califórnia, foram registradas por Churchman (1967). Apenas após a apresentação dessa conceituação em eventos acadêmicos, os pesquisadores em planejamento regional Rittel e Webber (1973) propuseram o conceito de Wicked Problems para os problemas da pós-modernidade, decorrentes da crescente metropolização dos EUA, como habitações precárias, mobilidade urbana ou o tráfico de drogas. Esses problemas compartilham certas características:

\footnotetext{
${ }^{2}$ Tradução livre pelo autor.
} 
- Cada problema é único, mais que complexo, e constitui sintoma de diversos outros problemas subjacentes.

- Não existe uma definição única ou objetiva do problema, existem múltiplas propostas para solução, em princípio, todas válidas.

- Não existe uma solução certo/errado para lidar com esses problemas, apenas a escolha entre melhor/pior mediante observação empírica.

- Esses problemas não possuem solução definitiva, existe apenas a possibilidade de controlar os impactos, minimizar a expansão, planejando e replanejando continuamente.

A minimização de um problema dessa natureza depende da mudança de comportamento de elevado número de atores sociais envolvidos com a situação. Tal desafio é raro e difícil de se obter, em geral apenas após uma crise severa. Rittel (1972) enfatizou que o processo de tomada de decisão envolve criatividade e inovação e propôs a adoção de um enfoque participativo para lidar com Wicked Problems. No mesmo período, porém, diante da desilusão com a empiria das políticas públicas inclusivas, Arnstein (1969) elaborava sua visão crítica quanto às ferramentas participativas de planejamento.

O êxito do Protocolo de Montreal, deliberado em 1987, que estipula o fim da produção e comercialização de aerossóis que causam o buraco da camada de ozônio (BRASIL, 2012) representa um dos poucos exemplos positivos de como planejar de forma participativa, mobilizando grande número de atores para intervir em um Wicked Problem. O Acordo de Paris, firmado em 2015, representa tentativa de replicar o mecanismo com relação à minimização da mudança do clima, cujos resultados ainda precisam ser monitorados para uma avalição conclusiva.

Diversos testes para renovação do planejamento territorial, sintetizados a seguir, superam os limites administrativos do planejamento focado no Estado, qual seja, municípios ou Estados, e trabalham em bacias hidrográficas. As alterações atmosféricas não respeitam limites administrativos. Pelo próximo século os impactos da mudança do clima serão sentidos essencialmente pela alteração no regime hídrico, a sociedade e a economia serão afetadas no âmbito das bacias hidrográficas.

No RS, a Região Hidrográfica do Guaíba, estabelecida pela Lei Estadual 10.350, de 30/12/1994, constitui território privilegiado para análise da evolução de modelos concorrentes de planejamento territorial. O paradigma do Desenvolvimentismo pode ser representado pelo município de Triunfo, historicamente baseado na pecuária extensiva. Em 1976, sem consulta ou engajamento pela sociedade, o governo militar decidiu instalar em Triunfo o 3o Polo Petroquímico do país (FREIRE; VILLAS-BÔAS, 2000). Assim, este se tornou o município com a maior renda per capita do Estado e uma das cidades de pequeno porte mais ricas da Federação (PEREIRA; NAKABASHI; SACHSIDA, 2011), sendo exposto aos impactos da "Doença Holandesa", incluindo denúncias recorrentes de corrupção que lhe valeram a alcunha de "território dos escândalos" (BRUM, 2005). O investimento concentrador de capital, ao invés do efeito irradiador de contribuição para o desenvolvimento regional, criou um enclave (FIALKOW, 2014).

Na Região Hidrográfica do Guaíba estão sendo testados modelos diversos de desenvolvimento territorial, mediante planejamento e ação por atores locais. Na bacia do Rio Taquari, o apagão do verão de 2014 gerou prejuízos estimados em R\$ 5,4 milhões 
pela mortandade de aves nos galpões sem refrigeração, e a perda de leite estocado em resfriadores individuais ou comunitários. $O$ desastre despertou lideranças empresariais para a fragilidade do sistema de distribuição de energia e iniciou-se uma mobilização inédita no Estado pela autossuficiência na geração descentralizada de energia. A proposta prevê liderança pelas cooperativas regionais, com a Cooperativa Languiru obtendo cooperação da Alemanha para teste de produção de biogás a partir de dejetos de granja de suínos, enquanto a Cooperativa Certel promove a instalação de pequenas centrais hidrelétricas ao longo do Rio Forqueta (BENCKE, 2014; CIC VT, 2017).

Na bacia do Rio Pardo está sendo conduzida a primeira e única experiência de pagamento por serviços ambientais do Estado. Na sub-bacia do Arroio Andreas, uma parceria entre empresas locais e a Universidade de Santa Cruz do Sul criou o Programa Protetor das Águas, para recuperação de áreas de nascente e a vegetação de áreas de proteção permanente (OLIVEIRA et al., 2014). A administração municipal de Vera Cruz incorporou a experiência como política pública, que passou a receber apoio da Agência Nacional de Águas (SANTOS; SILVANO, 2016).

Santa Cruz do Sul tornou-se polo de microgeração de energia fotovoltaica (BORGES, 2017). Encontra-se em expansão um nicho de inovação composto por empresas integradoras de sistemas fotovoltaicos, prestadores de serviços de instalação e manutenção, com linha de financiamento mantida pela Cooperativa Sicredi, que está possibilitando iniciativas pioneiras, como instalação de microusinas fotovoltaicas em propriedade arrozeira, ou a instalação de usina fotovoltaica em hospital beneficente.

Na região do Alto Vale do Rio Itajaí/SC foi estabelecido um fórum que aplica a metodologia do Diálogo Florestal, reunindo representantes de empresas do setor de base florestal, organizações ambientalistas, movimentos sociais e instituições públicas com objetivo de construir uma agenda comum. A partir dessa plataforma vêm sendo promovidas técnicas participativas de planejamento de paisagens, buscando integrar os interesses diversos aos recursos disponíveis na bacia hidrográfica (PROCHNOW, 2005, 2015; MELO, 2008).

Carmo e Anazawa (2017), pesquisadores da Universidade Estadual de Campinas, argumentam que por default, pela não decisão do Estado, foi estabelecida em ação emergencial uma conexão física entre as Regiões Metropolitanas de São Paulo e Rio de Janeiro. Somadas, ambas as regiões congregam 328 municípios. O compartilhamento de recursos hídricos para enfrentar a crise hídrica de 2014/2015 teria criado de facto nova espacialidade, que os autores denominam de Hidromegalópole São Paulo-Rio de Janeiro. A transposição de águas da Bacia do Paraíba do Sul, para a Bacia Piracicaba-Capivari-Jundiaí, minimizou a crise, porém não representa uma solução permanente para a escassez hídrica nesse território, no qual se aglomeram cerca de 46 milhões de habitantes.

O rompimento da barragem do Fundão, em novembro de 2015, despejando 32 milhões de $\mathrm{m}^{3}$ de rejeitos de mineração na Bacia do Rio Doce, entre Minas Gerais e o Oceano Atlântico, expôs a desconfiança de representantes do governo federal na capacidade de planejamento por parte do Estado. Visando a evitar o acúmulo de demandas judicias, foi negociada a reparação no valor de até $\mathrm{R} \$ 20$ bilhões pela empresa Samarco, a serem investidos na recuperação e no desenvolvimento da bacia por 15 anos. Esses recursos não passam por instâncias subnacionais democraticamente eleitas, os gover- 
nos estaduais ou municipais, mas serão alocados por meio de uma organização privada, a Fundação Renova, criada em 2016. A terceirização do desenvolvimento territorial constitui uma novidade na paisagem institucional brasileira, a ser monitorada conforme avança a instituição dos 41 programas de ação.

Passando ao largo do tradicional planejamento estatal, que se materializa nos Planos Plurianuais, ou das instâncias participativas de debate do desenvolvimento, como conselhos e fóruns, observamos, ao longo da última década, o teste de diversas inovações no planejamento territorial, seja no RS, especificamente na Região Hidrográfica do Guaíba, ou em outras regiões, como os exemplos citados em Santa Catarina, São Paulo, Rio de Janeiro e Minas Gerais. Essas inovações têm sido decorrentes de ações emergenciais, ou seja, sem planejamento estratégico, ou são oriundas de iniciativa voluntária e espontânea por empreendedores locais.

Esse diversificado cenário sugere uma renovação da pauta de pesquisa sobre o planejamento regional no RS, hoje bastante apegada ao ideário do Desenvolvimentismo. Segundo Beck, interessa em especial identificar os atores locais e as relações de poder que estão possibilitando nichos de inovação que diversificam as opções de intervenção territorial, para além dos clássicos binômios agricultura familiar/agronegócio, zona rural/área urbana, trabalho/capital e similares. Assim, criam-se novas opções e, também, novos desafios para o engajamento cidadão, além de novos custos para a ação estatal.

\section{CONCLUINDO:}

\section{Avanços Possíveis Rumo à Maior Resiliência}

A mudança do clima representa um desafio em longo prazo. Desafio que demanda planejamento com visão estratégica e capacidade de mobilizar largos recursos de modo sustentado para a resiliência, contradizendo a atual capacidade do Executivo gaúcho, restrito em seu raio de ação pelo déficit fiscal previsto para durar ao menos três décadas. O paradigma do Desenvolvimentismo, característica central da cultura gaúcha, parece esgotado. Com esse, esgotaram-se as capacidades das ferramentas de planejamento territorial e acesso ao orçamento estadual, como Consulta Popular, Orçamentos Participativos e Conselhos Regionais de Desenvolvimento.

Simultaneamente, economia e sociedade do RS enfrentam novos desafios pelo aumento da temperatura média que influencia na produtividade das lavouras, escassez prolongada de recursos hídricos ou o acúmulo de alagamentos em áreas urbanas. Ampliam-se as incertezas e os riscos, que não apenas afetam famílias ou empresas vulneráveis, mas, potencialmente, atingem a todos. Os riscos são democratizados e a capacidade de resposta pelo Estado, reduzida. Essa situação apresenta afinidade com o conceito de Sociedade de Risco, proposto por Beck. Assim, podemos inferir que o RS se encontra em transição para a Sociedade de Risco.

Beck enfatiza que, pelos custos que incorrem a curto prazo, políticas de longo prazo para adaptação à mudança do clima dependem de decidido apoio pelos eleitores e pelos contribuintes. Em outras palavras, de novas formas de participação. Para operacionalizar essa agenda de intervenção na economia, Giddens propõe um novo pacto social, o New Green Deal. Nesse sentido, mudança do clima não se restringe a um "tema 
ambiental", afeta a sociedade e seu modelo de desenvolvimento como um todo. E o planejamento territorial passa a enfrentar desafios maiores, necessitando incorporar incertezas e riscos.

Estabelecido esse entendimento, as Ciências Sociais encontram-se diante de uma demanda de renovação e adequação de sua agenda de pesquisa. Há necessidade de novas formas de engajamento e participação, pelo cidadão e pela iniciativa privada. Não advogamos necessariamente a criação de novos métodos de planejamento. Um exemplo das possibilidades reside na expansão do horizonte territorial do planejamento, ultrapassando as restritas dimensões das delimitações administrativas entre municípios para abarcar as bacias hidrográficas como unidade de planejamento e pesquisa. Adquirem, assim, nova relevância os comitês de gestão de bacia, que deixam de ser mera instância consultiva por parte dos órgãos ambientais, para tornarem-se arena de conflitos entre usuários e produtores da água.

Existem indicativos suficientes de que a mudança climática se faz sentir no RS. Esses impactos devem crescer em intensidade nas próximas décadas. A rica base de debates, conflitos e experiências da cultura gaúcha quanto a mecanismos de participação, constitui uma base promissora para introdução e teste de novos modelos de planejamento regional que promovam a resiliência e que superem a dependência do Estado como principal indutor de inovações.

\section{REFERÊNCIAS}

ARNSTEIN, S. A Ladder of Citizen Participation. Journal of the American Institute of Planners, Austin, v. 35, n. 4, p. 216-224, 1969.

AVZARADEL, P. Encostas, extremos climáticos e riscos: um estudo da irresponsabilidade organizada nas ocupações irregulares na Região Serrana/RJ. 2012. Tese (Doutorado) -Universidade Estadual do Rio de Janeiro, Rio de Janeiro, 2012.

BECK, U. Climate for Change, or How to Create a Green Modernity? Theory, Culture \& Society, London, v. 27, n. 2-3, p. 254-266, 2010a.

BECK, U. Sociedade de risco. São Paulo: Editora 34, $2010 \mathrm{~b}$.

BECK, U. Schöne neue Arbeitswelt. Frankfurt: Suhrkamp, 1999.

BECK, U. Gegengifte: die organisierte Unverwantwortlichkeit. Frankfurt: Suhrkamp, 1988.

BENCKE, J. Vale pode ser autossuficiente na geração de energia. 28/10/2014. Disponível em: https:// www.informativo.com.br/geral. Acesso em: 4 maio 2017.

BORGES, N.. É hora de aproveitar o sol para gerar energia. 17/06/2017. Disponível em: https://www.gaz. com.br/conteudos/regional. Acesso em: 5 jun. 2018.

BRASIL. MINISTÉRIO DO MEIO AMBIENTE. Programa Brasileiro de Eliminação dos HCFCs-PBH. Brasília, 2012.

BRUM, M. Triunfo: território dos escândalos. Zero Hora. 2005. Disponível em: https://tce-rs.jus.brasil. com.br. Acesso em: 18 mar. 2018.

CARMO, R.; ANAZAWA, T. Hidromegalópole São Paulo-Rio de Janeiro: escassez hídrica, sobreposição de espacialidades e conflitos. Boletim Regional, Urbano e Ambiental-Ipea, Brasília, v. 17, p. 61-68, 2017.

CENTRO DE GESTÃO E ESTUDOS ESTRATÉGICOS. A ciência e a tecnologia no olhar dos brasileiros: percepção pública da C\&T no Brasil-2015. Brasília, 2017.

CHURCHMAN, W. Wicked Problems. Management Science, Michigan, v. 14, n. 4, p. B-141-142, 1967.

CIC VT. Região quer ser autossuficiente na produção de energia elétrica. 14/02/2017. Disponível em: https://cicvaledotaquari.com.br. Acesso em: 10 maio 2018.

FIALKOW, J. Determinantes regionais da desigualdade de renda no RS, 2000/10. 2014. Dissertação (Mestrado) -Universidade Federal de Minas Gerais, Belo Horizonte, 2014.

FOCHEZATTO, A.; GRANDO, M. Efeitos da estiagem de 2008 na economia do RS: uma abordagem multisetorial. Ensaios FEE. Porto Alegre, v. 32, n 1, p. 137-160, 2011. 
FREIRE, J.; VILLAS-BÔAS, M. Pólo Petroquímico de Triunfo: instalação, empresas, produtos. Indicadores Econômicos - FEE, Porto Alegre, v. 28, p. 1, p. 49-65, 2000.

GIDDENS, A. The Politics of Climate Change: National Responses to the Challenge of Global Warming. London: Policy Network Paper, 2008.

GIMÉNEZ, A. Climate Change and Variability in the Mixed Crop/Livestock Production Systems of the Pampa. Montevideo: Instituto Nacional de Investigación Agropecuaria, 2006.

MELO, T. (org.) Sementes do diálogo: registros da primeira fase do Diálogo Florestal para a Mata Atlântica (2005-2007). Rio de Janeiro: Instituto BioAtlântica, 2008.

OLIVEIRA, P.; DELEVATI, D.; COSTA, A.; ALCAYAGA, E. Avaliação da qualidade da água de nascentes na bacia hidrográfica do Arroio Andréas/RS. Revista Jovens Pesquisadores, Santa Cruz do Sul, v. 4, n. 1, p. 32-41, 2014.

PEREIRA, A.; NAKABASHI, L.; SACHSIDA, A. Qualidade das instituições e PIB per capita nos municípios brasileiros. Brasília: Ipea, 2011. (Texto para Discussão, n. 1.623).

PROCHNOW, M. (org.). Diálogo entre setores: integrando espaços e paisagens da produção rural e conservação. Atalanta: Apremavi, 2015. (Cadernos do Diálogo, V. 6).

PROCHNOW, M. (org.). Planejando propriedades e paisagens. Rio do Sul: Apremavi; Curitiba: Fundação $O$ Boticário, 2005.

RITTEL, H. On the Planning Crisis: Systems Analysis of the 'First and Second Generation'. Berkeley: University of California Press, 1972.

RITTEL, H.; WEBBER, M. Dilemmas in a General Theory of Planning. Policy Sciences, San Francisco, v. 4, p. 155-169, 1973.

SANTOS, F.; SILVANO, R. Aplicabilidade, potenciais e desafios dos pagamentos por serviços ambientais para conservação da água. Desenvolvimento e Meio Ambiente, Curitiba, v. 38, p. 481-498, 2016.

SCOTTÁ, F. Análise da influência dos elementos do clima na vegetação campestre da Depressão Central, bioma Pampa. 2013. Dissertação (Mestrado) - Universidade Federal do Rio Grande do Sul, Porto Alegre, 2013. 